\title{
Martian Redox Chemistry: Oxygen Reduction in Low Temperature Magnesium Perchlorate Brines
}

Joseph Elliott, Kamonwad Ngamchuea, Christopher Batchelor-McAuley and Richard G. Compton*

* corresponding author: Richard G. Compton, Department of Chemistry, Physical \& Theoretical Chemistry Laboratory, University of Oxford, South Parks Road, Oxford, OX1 3QZ, United Kingdom

Email: richard.compton@chem.ox.ac.uk. Tel: +44(0)1865275957 Fax:+44(0)1865275410

\begin{abstract}
NASA has a mandate to send humans to Mars by 2033. Recent discoveries regarding Mars include the likely presence of low temperature liquid brines on the planet's surface. This work investigates redox chemistry in near saturated aqueous $2.8 \mathrm{M} \mathrm{Mg}\left(\mathrm{ClO}_{4}\right)_{2}$ at temperatures as low as $-34^{\circ} \mathrm{C}$. These conditions are comparable to those thought to be found on the Martian surface. In particular electro-reduction of oxygen is studied and the diffusion coefficient and solubility of this important redox species established.
\end{abstract}

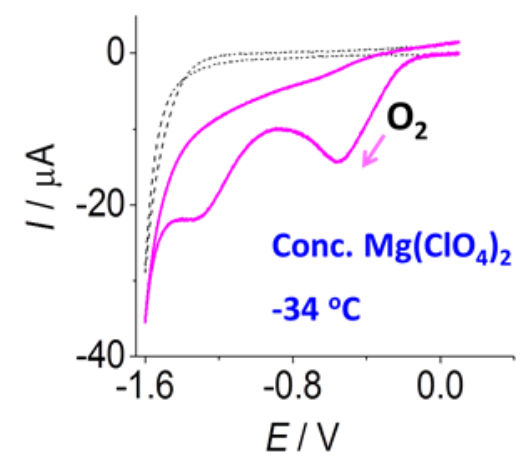




\section{Main Text}

The 2008 Phoenix lander mission to Mars went with the objective of studying the history of water in the Martian artic and to search for evidence of a habitable zone. ${ }^{1}$ In order to address these questions the lander was equipped with a range of analytical devices, including a wet chemistry laboratory (WCL). The WCL comprised of an array of 26 sensors, with the aim of yielding chemical information regarding the composition of the Martian soil. ${ }^{2}$ Included on this device was a gold microelectrode array ${ }^{3}$ suitable for use in heavy metal detection via anodic stripping voltammetry. ${ }^{4}$ Arguably the most significant discovery made using the WCL was the presence of high concentrations of perchlorates, as also indicated in the results of the Pheonix Thermal and Evolved Gas Analyzer. ${ }^{5}$

With an average surface temperature of around $-63^{\circ} \mathrm{C},{ }^{6}$ the Martian and near sub-surface region is a very cold environment. Consequently, although a significant amount of water likely still exists on Mars, ${ }^{7}$ the majority of this material will be frozen. ${ }^{8}$ However, although the average temperature is low the local temperature can vary widely depending on position, season and time; due to the thin atmosphere present, the Martian surface experiences large diurnal temperature variations (daily temperature range cf. 100K). ${ }^{9}$ High aqueous perchlorate concentrations strongly depress the freezing point of water to below $-60^{\circ} \mathrm{C}$. Moreover, these perchlorates are deliquescent and may remove water vapour from the atmosphere. Consequently, even in these comparatively cold conditions it is reasonable that local volumes of liquid water may temporarily form on the Maritain surface. It is the flow of these local brine formations that have been implicated as being the possible contemporary source of geographical features present on sloping Martian surfaces. ${ }^{10}$ Apart from being of distinct importance in terms of understanding the hydrological cycle and as potential sites for the existence of extra-terrestrial life, the presence of these low temperature brines presents an interesting environment under which aqueous chemistry can occur. The physical chemistry of high ionic strength media remains relatively under studied and is often reliant upon semiempirical approaches. ${ }^{11-12}$ Near-saturated perchlorate brines likely share many characteristics with room temperature ionic liquids.

As a fundamental class of reactions, electron transfer underpins a wide variety of both biological and environmental processes, playing an important role in a range of organic reactions. On Earth oxygen is integral in the cellular respiration of many species, however a 
number of extremeophiles exist which are known to utilise other energy sources. ${ }^{13}$ The composition of the Martian atmosphere is $96 \pm 0.7 \% \mathrm{CO}_{2}$ and only $0.145 \pm 0.09 \% \mathrm{O}_{2},{ }^{14}$ consequently any life forms that may be present may plausibly rely on a non-oxygen energy source. However, understanding the physical behaviour of oxygen in these low temperature brines is still of distinct interest both from a biological and geochemical standpoint. First, in part due to its small size the mass-transport of oxygen in the solution phase is often not well described by the classical 'Stokes-Einstein' equation. ${ }^{15}$ Second, as with most non-polar gases the dissolution of oxygen is endergonic $\left(\Delta \mathrm{G}_{\text {solv }}>0\right) ;{ }^{16}$ this arises predominantly due to the process being entropically unfavourable, with the enthalpic contribution being small but negative. As a result of the negative enthalpy of solvation, the solubility of most non-polar gases increases with decreasing temperature.

A recent mandate by the US government has asked NASA to aim to send humans to Mars by 2033. ${ }^{17-18}$ In the meantime, questions regarding the local Martian environment may usefully be studied in vitro. This work demonstrates how first voltammetric measurements in lowtemperature brines can be successfully undertaken, as opposed to low-temperature studies in non-aqueous solvents previously reported. ${ }^{19-21}$ Hence, indicating the likely feasibility of making direct voltammetric measurements for environmental monitoring on the Martian surface. Second, as a model system, the behaviour of oxygen is studied in this low temperature brine yielding quantitative thermodynamic and kinetic information.

The use of macro-electrode voltammetry for measurements of the redox activity of a molecular species in a low temperature brine was validated by measurement of the response of the reversible redox probe ferrocenemethanol. Cyclic voltammetry of $1.0 \mathrm{mM}$ ferrocenemethanol oxidation at a glassy carbon macro-electrode was recorded in $0.10 \mathrm{M}$ and 2.8 $\mathrm{M} \mathrm{Mg}\left(\mathrm{ClO}_{4}\right)_{2}$ supporting electrolytes at 25 and $-34.0^{\circ} \mathrm{C}$. The potentials were initially scanned anodically from -0.15 to $0.35 \mathrm{~V}$ vs Ag, then reversed back to $-0.15 \mathrm{~V}$ vs Ag at a series of scan rates in the range of 12.5 to $400 \mathrm{mV} \mathrm{s}^{-1}$. All measurements took place in a thermostated Faraday cage. The temperature was lowered down to $-34.0{ }^{\circ} \mathrm{C}$ using a dry-ice bath based on ethylene glycol mixtures. ${ }^{22}$ This work uses a near saturated solution phase molarity of $2.8 \mathrm{M}$ and studies the temperature down to $-34.0^{\circ} \mathrm{C}$. Lower temperatures can be achieved by increasing concentrations of the brine. At room temperature magnesium perchlorate is soluble up to a molality of $\sim 4.5 \mathrm{~mol} \mathrm{~kg}^{-1}$; however, the lowest freezing point 
$\left(-68.6^{\circ} \mathrm{C}\right)$ can be attained with a solution of $3.5 \mathrm{~mol} \mathrm{~kg}{ }^{-1} \cdot{ }^{23}$ The process is however exceedingly difficult to realize due to the extremely slow kinetics of dissolution.

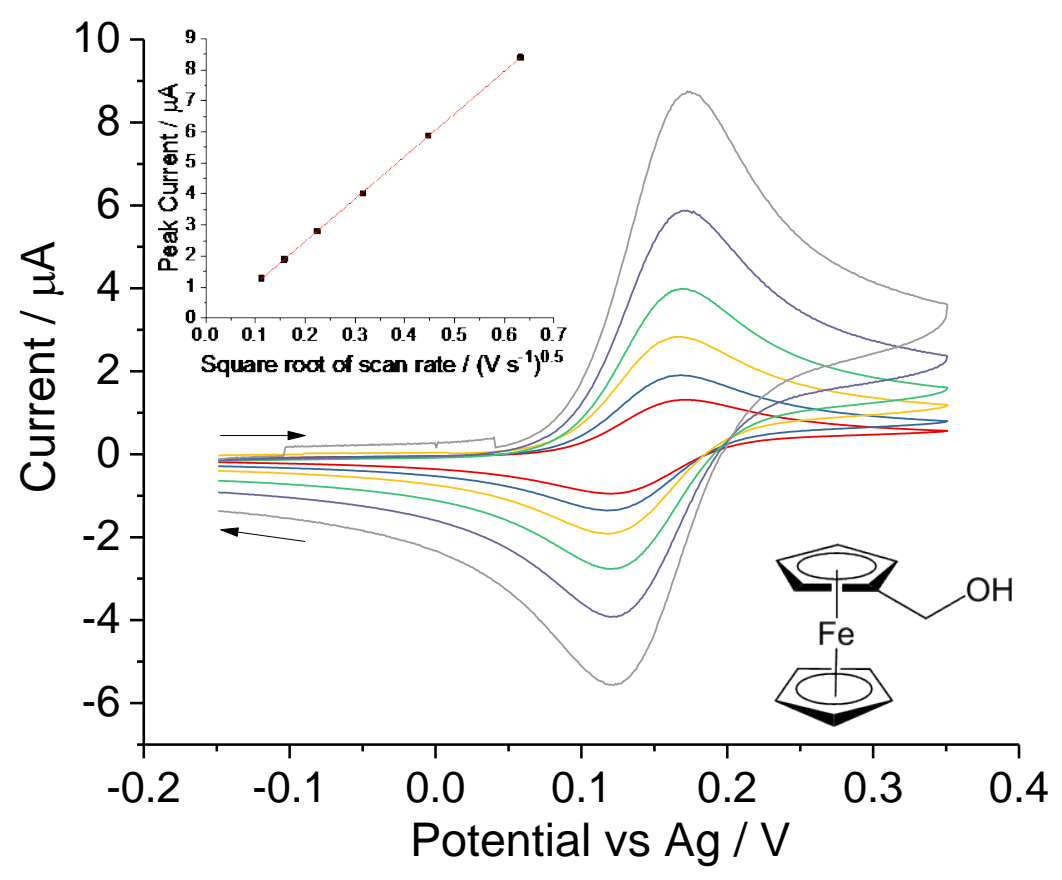

Figure 1: The voltammetric oxidation of $1 \mathrm{mM}$ ferrocenemethanol in an aqueous solution of

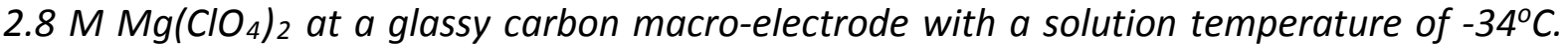
Voltammetric response measured at a series of scan rates in the range of $12.5-400 \mathrm{mV} \mathrm{s}^{-1}$.

Figure 1 depicts the voltammetric response of the reversible ferrocenemethanol/ ferrociniummethanol redox couple in a $2.8 \mathrm{M} \mathrm{Mg}\left(\mathrm{ClO}_{4}\right)_{2}$ brine at $-34^{\circ} \mathrm{C}$. Measurement was made at a macro glassy carbon electrode as a function of scan rate $\left(0.0125-0.4 \mathrm{~V} \mathrm{~s}^{-1}\right)$. A clear reversible and non ohmically distorted voltammetric wave is observed corresponding to the one-electron oxidation of the molecular species. From the analysis of the peak current as a function of scan rate (inlay Figure 1) the diffusion coefficient of the molecular species can be determined through the use of the reversible Randles-Ševčík equation. ${ }^{24}$ In this low temperature brine the diffusion coefficient of ferrocenemethanol was measured to be $5.8 \pm 0.6$ $\mathrm{x} 10^{-11} \mathrm{~m}^{2} \mathrm{~s}^{-1}$. Through the use of the Stokes-Einstein equation a species diffusion coefficient $\left(\mathrm{D}, \mathrm{m}^{2} \mathrm{~s}^{-1}\right.$ ) may be related to the solution viscosity, ${ }^{25}$ 


$$
D=\frac{k_{B} T}{6 \pi \eta r_{e f f}}
$$

where $k_{B}$ is the Boltzmann constant $\left(1.38 \times 10^{-23} \mathrm{~J} \mathrm{~K}^{-1}\right), \mathrm{T}$ is the temperature $(\mathrm{K}), \eta$ is the solution viscosity (Pa s) and $r_{\text {eff }}$ is the effective molecular radius (m) ${ }^{25}$ Note in the case of molecular species the strict applicability of this model is limited. At room temperature and in $0.1 \mathrm{M} \mathrm{KCl}$ solution the diffusion coefficient of this species has been previously determined to be $7.81 \times 10^{-10} \mathrm{~m}^{2} \mathrm{~s}^{-1} \cdot{ }^{26}$ This significant change in the mass-transport of the molecular species reflects the change in viscosity of the solution arising both from the used low temperature and the high salt concentration. For comparison at room temperature $\left(25^{\circ} \mathrm{C}\right)$ the viscosity of a $2.9 \mathrm{M} \mathrm{MgCl}_{2}$ solution is 3.1 times greater than water. ${ }^{27}$ Second, assuming the solutions viscosity follows an Arrenhius type relationship then the diffusional activation energy for a spherical particle in pure water is $18.1 \mathrm{~kJ} \mathrm{~mol}^{-12829}$ i.e. crude extrapolation from 25 to $-34^{\circ} \mathrm{C}$ predicts a factor of 6.1 decrease in the diffusion coefficient. Hence, on the basis of the above values the diffusion coefficient for ferrocenemethanol is estimated to be a factor of 19.1 times lower at $-34^{\circ} \mathrm{C}$ as compared to $25^{\circ} \mathrm{C}$, this is in reasonable agreement with the experimentally determined ratio of 13.5 .

Oxygen reduction was next studied in $2.8 \mathrm{M} \mathrm{Mg}\left(\mathrm{ClO}_{4}\right)_{2}$ supporting electrolyte at different temperatures $\left(-31.0,-14.5,5.0\right.$ and $\left.25.0^{\circ} \mathrm{C}\right)$. High purity oxygen gas was vigorously bubbled into the solutions for $5 \mathrm{~min}$ to ensure saturated oxygen concentrations under the studied conditions; Section S2 (SI). Cyclic voltammetry of oxygen reduction was then recorded. The potentials were swept at a series of scan rates $\left(12.5-400 \mathrm{mV} \mathrm{s}^{-1}\right)$. A glassy carbon macro-, a carbon micro- or a gold micro-electrode was used as a working electrode.

In an aqueous environment oxygen reduction is a multi-electron, multi-proton process leading to either the production of water or the intermediate hydrogen peroxide. ${ }^{30}$ On both gold and carbon surfaces the reduction follows a step-wise mechanism predominantly resulting, at relatively low overpotentials, in the formation of the two-electron product hydrogen peroxide. In the following work, all 'macro' electrode measurements were made using a glassy carbon electrode. However, the 'micro' electrode results were recorded on either a carbon or gold microelectrode; the low temperatures were found to irreversibly damage the carbon microelectrodes, probably due to mechanical contraction and fracturing of the material. Note 
that although $\mathrm{CO}_{2}$ also exists at high concentrations on Mars, no cathodic responses of $\mathrm{CO}_{2}$ were observed in low-temperature brines and hence the presence of $\mathrm{CO}_{2}$ is expected not to interfere with the electrochemical responses of $\mathrm{O}_{2}$ reduction studied herein (SI).
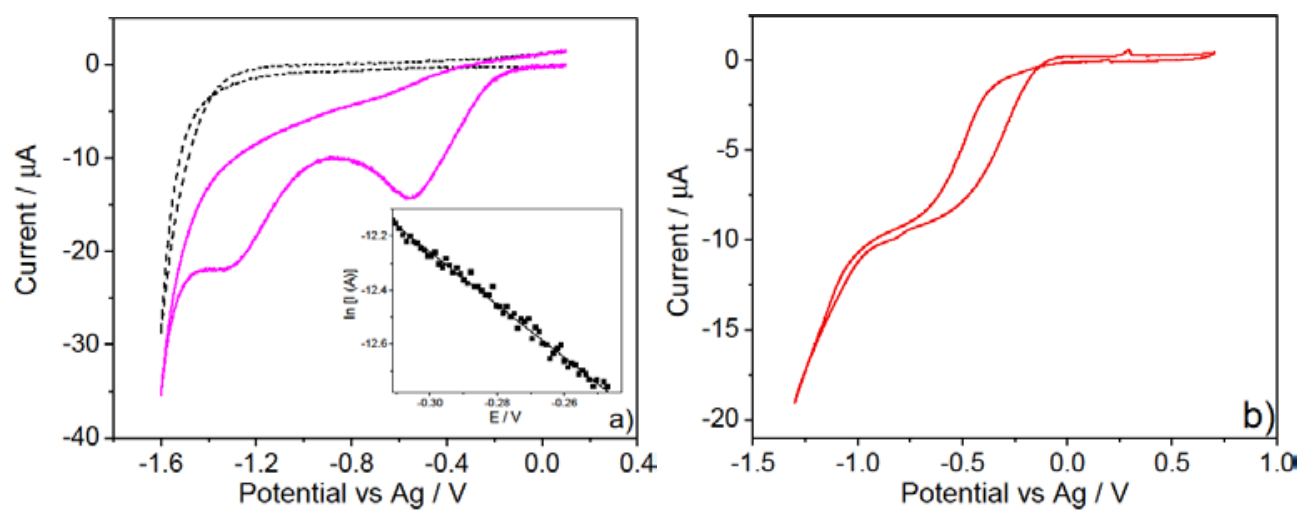

Figure 2: The reduction of oxygen on a) a macro glassy carbon electrode (radius $=1.5 \mathrm{~mm}$ ) and b) a carbon microdisc electrode (radius $=24.7 \mu \mathrm{m})$. Recorded in $2.8 \mathrm{M} \mathrm{Mg}\left(\mathrm{ClO}_{4}\right)_{2}$ at a) $200 \mathrm{mVs}-1$ and b) $10 \mathrm{mVs}-1\left(25^{\circ} \mathrm{C}\right)$.

Figure 2 presents the reduction of oxygen at carbon macro and micro electrodes as measured at $25^{\circ} \mathrm{C}$ in $2.8 \mathrm{M} \mathrm{Mg}\left(\mathrm{ClO}_{4}\right)_{2}$. At the macroelectrode, a clear irreversible reduction is observed with two voltammetric peaks situated at -0.55 and $-1.31 \mathrm{~V}$ (vs Ag pseudo ref). The first wave at $-0.55 \mathrm{~V}$ corresponds to the two-electron reduction of oxygen to hydrogen peroxide (SI Figure S2). ${ }^{30}$ Analysis using the irreversible form of the Randles-Ševčík equation ${ }^{24}$ together with Tafel analysis reveals the transfer coefficient of the rate determining step (RDS) to be $0.26 \pm 0.01$, indicating that the first electron transfer is the RDS. The presence of the high salt concentration will lead to a significant decrease in the solubility of the oxygen. Consequently, under the two-electron transfer assumption, both concentration (C) and diffusion coefficient (D) are only unknowns. From this macroelectrode experiment performed as a function of scan rate the product of $\mathrm{DC}^{2}$ is determined to be $1.6 \times 10^{-10} \mathrm{~mol}^{2} \mathrm{~m}^{-4} \mathrm{~s}^{-1}$ at $25^{\circ} \mathrm{C}$.

In order for the magnitude of $\mathrm{D}$ and $\mathrm{C}$ to be independently assessed the voltammetric reduction of oxygen needs to be performed under different mass-transport conditions. In optimal cases where a simple redox reaction is occurring this can be achieved simply through a single chronoamperometric experiment, ${ }^{31}$ however, in the present case the more complicated reaction pathway prohibits such a methodology. Hence, the reduction of oxygen 
was independently studied at a carbon micro disc electrode (Figure 2 B). The mass-transport limited flux to a microdisc electrode is analytically given by: ${ }^{32}$

$$
I_{s S}=4 n F D C r
$$

where $I_{\mathrm{ss}}$ is the diffusion limited current, $n$ is the number of electrons transferred, $F$ is the Faraday constant (96495 $\mathrm{C} \mathrm{mol}^{-1}$ ), $D$ is the diffusion coefficient, $C$ is the concentration and $r$ is the radius of the electrode. At $25^{\circ} \mathrm{C}$ the solubility of oxygen in $2.8 \mathrm{M} \mathrm{Mg}\left(\mathrm{ClO}_{4}\right)_{2}$ was found to be $0.28 \pm 0.02 \mathrm{mM}$, with an associated diffusion coefficient of $2.1 \pm 0.1 \times 10^{-9} \mathrm{~m}^{2} \mathrm{~s}^{-1}$. Two important insights come from these values. First, in the absence of salt the solubility of oxygen in pure water is $1.28 \mathrm{mM}$ (at $298 \mathrm{~K}$ ). For $\mathrm{MgCl}_{2}$ the associated Sechenov salting out parameter is $0.222 \mathrm{~L} \mathrm{~mol}^{-1} \cdot{ }^{16}$ Hence, at $2.8 \mathrm{M} \mathrm{MgCl}_{2}$ the solubility of oxygen is $0.37 \mathrm{mM}$, given the different anion identity the experimentally determined decrease of a factor of 4.6 is in good consistency with the literature. In the absence of salt the oxygen diffusion coefficient is found within the literature to be $2.4 \times 10^{-9} \mathrm{~m}^{2} \mathrm{~s}^{-1} \cdot 33$ Consequently, within the present work in $2.8 \mathrm{M} \mathrm{Mg}\left(\mathrm{ClO}_{4}\right)_{2}$ the oxygen diffusion coefficient is found to be relatively unaltered by the presence of the high electrolyte concentration. This is in contrast to the response of ferrocenemethanol where the diffusion coefficient is found to decrease by a factor of $\sim 2.8$ when in the presence of $2.8 \mathrm{M} \mathrm{Mg}\left(\mathrm{ClO}_{4}\right)_{2}$ as compared to pure water (see SI section 3 for further details).

Using the methodology described above involving voltammetric experiments performed under two different mass-transport regimes the oxygen diffusion coefficient and solubility can be determined as a function of the solution temperature. Examples of the raw voltammetric data are presented in the SI section 4. Figure 3 presents the variation of the oxygen solubility (Figure 3a) and diffusion coefficient (Figure 3b) as a function of the temperature. Analysis of the variation of the natural log of the oxygen solubility against the inverse temperature (Van’t Hoff equation), yields a measure of the enthalpy of solvation for oxygen in the concentrated brine, here yielding a value of $\Delta \mathrm{H}_{\mathrm{solv}}=-15 \pm 0.5 \mathrm{~kJ} \mathrm{~mol}^{-1}$. 

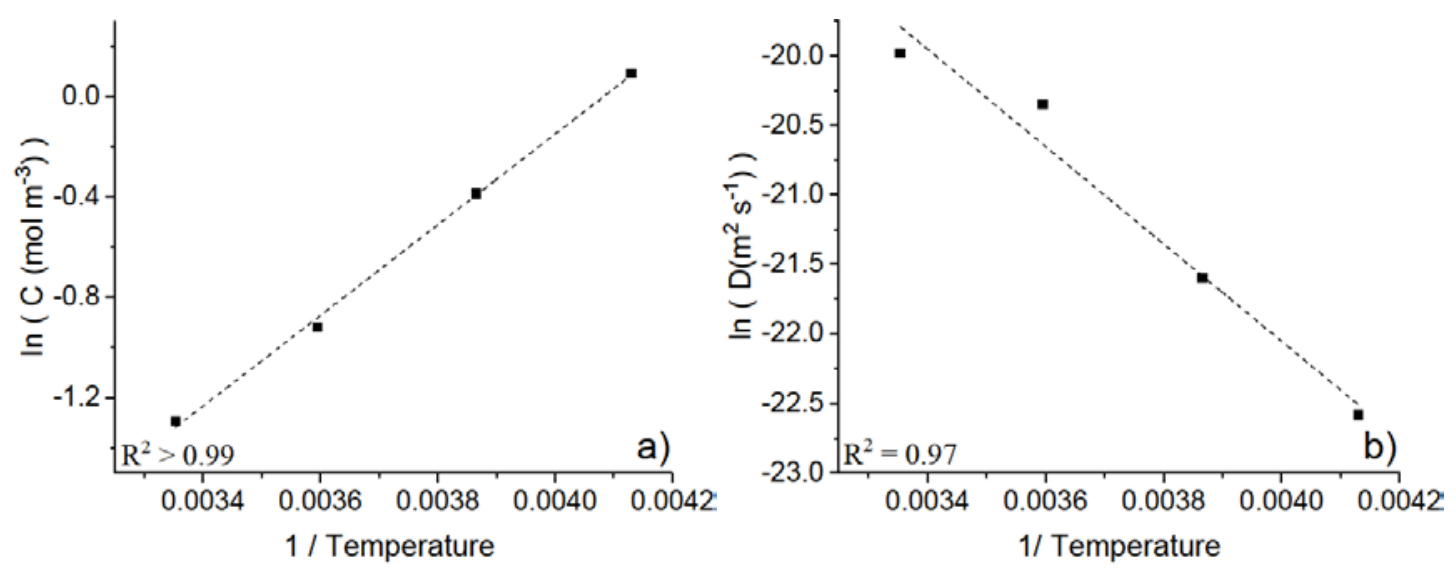

Figure 3: Variation of a) the oxygen solubility and b) the oxygen diffusion coefficient in $2.8 \mathrm{M}$ $\mathrm{Mg}(\mathrm{ClO} 4) 2$ as a function of temperature

In pure water at $298.15 \mathrm{~K}$ the enthalpy of solvation is $-12.11 \mathrm{~kJ} \mathrm{~mol}^{-1}$, decreasing to $-17.2 \mathrm{~kJ}$ $\mathrm{mol}^{-1}$ at $273.15 \mathrm{~K}^{16}$ Hence, given the significant change in the solubility of the oxygen in this high electrolyte environment as compared to pure water, this value is consistent with the salting-out of the gas being predominantly an entropic effect. This is fully consistent with the interpretation that salting-out of non-polar gases is dominated by exclusion of the gas from a significant volume of the solution due to ion hydration. In accordance with the Arrhenius equation, the diffusional activation energy of oxygen in this concentrated brine can be determined from Figure 3b to be $E_{a}=29 \pm 3.6 \mathrm{~kJ} \mathrm{~mol}^{-1}$ in $2.8 \mathrm{M} \mathrm{Mg}\left(\mathrm{ClO}_{4}\right)_{2}$. This value is significantly greater than that predicted on the basis of the Stokes-Einstein equation from the plot of $\ln (\mathrm{D})$ against $1 / \mathrm{T}\left(\mathrm{E}_{\mathrm{a}}=18.2 \mathrm{~kJ} \mathrm{~mol}^{-1}\right)$ but is in agreement with previously reported experimental values for the diffusional activation energy of oxygen in pure water $\left(E_{a}=\right.$ $\left.24.08 \pm 1.47 \mathrm{~kJ} \mathrm{~mol}^{-1}\right) .{ }^{33}$ The deviation of the diffusional activation energy from that predicted theoretically is likely due to the solute-solvent interaction such as hydrogen bonding between oxygen and water molecules.

\section{Conclusions}

The ability to study voltammetry in low temperature perchlorate brines comparable to those found on the Martian surface has been evidenced. This result indicates the possibility of performing electrochemically studies for use in direct environmental monitoring on the Martian surface. The physical properties of a low temperature magnesium perchlorate brine was studied by investigating the reduction of oxygen at both macro and micro electrodes 
enabling the diffusion coefficient and oxygen solubility to be determined. Measurements made as a function of temperature reveal the enthalpy of oxygen solvation in $2.8 \mathrm{M}$ $\mathrm{Mg}\left(\mathrm{ClO}_{4}\right)_{2}$ top be $-15 \pm 0.5 \mathrm{~kJ} \mathrm{~mol}^{-1}$ and the diffusional activation energy of the molecular oxygen to be $29 \pm 3.6 \mathrm{~kJ} \mathrm{~mol}^{-1}$. This activation energy is greater than that predicted for by the Stokes-Einstein equation but is very comparable to other literature values for the diffusion of oxygen in aqueous environments.

\section{Acknowledgements}

KN acknowledges funding from DPST scholarship, the Royal Thai government. This project is supported by the funding from the European Research Council under the European Union's Seventh Framework Programme (FP/2007-2013)/ERC Grant Agreement no. [320403].

\section{Supporting Information}

Chemical reagents and instrumentation; time required to saturate brine with oxygen; voltammetry of hydrogen peroxide on a gold micro-electrode; examples of oxygen reduction in $2.8 \mathrm{M} \mathrm{Mg}\left(\mathrm{ClO}_{4}\right)_{2}$ at different temperatures.

\section{References}

1. Goldstein, B.; Shotwell, R. Phoenix: The First Mars Scout Mission, 2009 IEEE Aerospace conference, Montana, USA, 2009.

2. Hecht, M. H.; Marshall, J.; Pike, W. T.; Staufer, U.; Blaney, D.; Braendlin, D.; Gautsch, S.; Goetz, W.; Hidber, H. R.; Keller, H. U. Microscopy Capabilities of the Microscopy, Electrochemistry, and Conductivity Analyzer. J. Geophys. Res.: Planets 2008, 113, E00A22.

3. Kounaves, S. P.; Hecht, M. H.; West, S. J.; Morookian, J. M.; Young, S. M. M.; Quinn, R.; Grunthaner, P.; Wen, X.; Weilert, M.; Cable, C. A.; et al. The MECA Wet Chemistry Laboratory on the 2007 Phoenix Mars Scout Lander. J. Geophys. Res.: Planets 2009, 114, E00A19.

4. Feeney, R.; Kounaves, S. P. On-Site Analysis of Arsenic in Groundwater Using a Microfabricated Gold Ultramicroelectrode Array. Anal. Chem. 2000, 72, 2222-2228.

5. Hecht, M. H.; Kounaves, S. P.; Quinn, R. C.; West, S. J.; Young, S. M. M.; Ming, D. W.; Catling, D. C.; Clark, B. C.; Boynton, W. V.; Hoffman, J. Detection of Perchlorate and the Soluble Chemistry of Martian Soil at the Phoenix Lander Site. Science 2009, 325, 64-67. 
6. Osczevski, R. Martian Windchill in Terrestrial Terms. Bull. Am. Meteorol. Soc. 2014, 95, 533-541.

7. Carr, M. H.; Head, J. W. Oceans on Mars: An Assessment of the Observational Evidence and Possible Fate. J. Geophys. Res.: Planets 2003, 108, 5042.

8. $\quad$ Smith, P. H.; Tamppari, L. K.; Arvidson, R. E.; Bass, D.; Blaney, D.; Boynton, W. V.; Carswell, A.; Catling, D. C.; Clark, B. C.; Duck, T. $\mathrm{H}_{2} \mathrm{O}$ at the Phoenix Landing Site. Science 2009, 325, 58-61.

9. $\quad$ Spanovich, N.; Smith, M. D.; Smith, P. H.; Wolff, M. J.; Christensen, P. R.; Squyres, S. W. Surface and Near-Surface Atmospheric Temperatures for the Mars Exploration Rover Landing Sites. Icarus 2006, 180, 314-320.

10. Ojha, L.; Wilhelm, M. B.; Murchie, S. L.; McEwen, A. S.; Wray, J. J.; Hanley, J.; Massé, M.; Chojnacki, M. Spectral Evidence for Hydrated Salts in Recurring Slope Lineae on Mars. Nat. Geosci. 2015, 8, 829-832.

11. Robinson, R. A.; Stokes, R. H. Electrolyte Solutions: Second Revised Edition. Dover Publications: New York, USA, 2012.

12. Ninham, B. W.; Nostro, P. L. Molecular Forces and Self Assembly: In Colloid, Nano Sciences and Biology. Cambridge University Press: Cambridge, UK, 2010.

13. Danovaro, R.; Dell'Anno, A.; Pusceddu, A.; Gambi, C.; Heiner, I.; Kristensen, R. M. The First Metazoa Living in Permanently Anoxic Conditions. BMC Biol. 2010, 8, 30.

14. Leshin, L. A.; Mahaffy, P. R.; Webster, C. R.; Cabane, M.; Coll, P.; Conrad, P. G.; Archer, P. D.; Atreya, S. K.; Brunner, A. E.; Buch, A. Volatile, Isotope, and Organic Analysis of Martian Fines with the Mars Curiosity Rover. Science 2013, 341, 1238937.

15. Li, Q.; Batchelor-Mcauley, C.; Lawrence, N. S.; Hartshorne, R. S.; Compton, R. G. Anomalous Solubility of Oxygen in Acetonitrile/Water Mixture Containing Tetra-nbutylammonium Perchlorate Supporting Electrolyte; The Solubility and Diffusion Coefficient of Oxygen in Anhydrous Acetonitrile and Aqueous Mixtures. J. Electroanal. Chem. 2013, 688, 328-335.

16. Battino, R.; Rettich, T. R.; Tominaga, T. The Solubility of Oxygen and Ozone in Liquids. J. Phys. Chem. Ref. Data 1983, 12, 163-178.

17. Trump, D., Tweet: 'Honored to sign S.442 today. With this legislation, we support @NASA's scientists, engineers, and astronauts in their pursuit of discovery!' 2017, https://t.co/Z5VwluvJQx.

18. S.442 - National Aeronautics and Space Administration Transition Authorization Act of 2017, 115th Congress (2017-2018), USA, 2017.

19. Donohoe, T. J.; Johnson, D. J.; Compton, R. G.; Wadhawan, J. D. Low Temperature Electrochemistry as a Mechanistic Probe for the Partial Reduction of Heterocycles. Tetrahedron 2004, 60, 5945-5952. 
20. Bond, A. M.; Fleischmann, M.; Robinson, J. The Use of Platinum Microelectrodes for Electrochemical Investigations in Low Temperature Glasses of Non-aqueous Solvents. J. Electroanal. Chem. Interfacial Electrochem. 1984, 180, 257-263.

21. Van Duyne, R. P.; Reilley, C. N. Low-temperature Electrochemistry. I. Characteristics of Electrode Reactions in the Absence of Coupled Chemical Kinetics. Anal. Chem. 2002, 44, 142-152.

22. Jensen, C. M.; Lee, D. W. Dry-ice Bath Based on Ethylene Glycol Mixtures. J. Chem. Educ. 2000, 77, 629.

23. Pestova, O. N.; Myund, L. A.; Khripun, M. K.; Prigaro, A. V. Polythermal Study of the Systems $\mathrm{M}\left(\mathrm{ClO}_{4}\right)_{2}-\mathrm{H}_{2} \mathrm{O}\left(\mathrm{M}^{2+}=\mathrm{Mg}^{2+}, \mathrm{Ca}^{2+}, \mathrm{Sr}^{2+}, \mathrm{Ba}^{2+}\right)$. Russ. J. Appl. Chem. 2005, 78, 409-413.

24. Batchelor-Mcauley, C.; Compton, R. G. Voltammetry of Multi-electron Electrode Processes of Organic Species. J. Electroanal. Chem. 2012, 669, 73-81.

25. Edward, J. T. Molecular Volumes and the Stokes-Einstein Equation. J. Chem. Educ. 1970, 47, 261-270.

26. Ngamchuea, K.; Lin, C.; Batchelor-Mcauley, C.; Compton, R. G. Supported Microwires for Electroanalysis: Sensitive Amperometric Detection of Reduced Glutathione. Anal. Chem. 2017, 89, 3780-3786.

27. Phang, S.; Stokes, R. H. Density, Viscosity, Conductance, and Transference Number of Concentrated Aqueous Magnesium Chloride at 25ㄷ. J. Solution Chem. 1980, 9, 497-505.

28. As estimated from the variation in the viscosity of pure water from 273 to $373 \mathrm{~K}$.

29. Korson, L.; Drost-Hansen, W.; Millero, F. J. Viscosity of Water at Various Temperatures. J. Phys. Chem. 1969, 73, 34-39.

30. Zhang, H.; Lin, C.; Sepunaru, L.; Batchelor-McAuley, C.; Compton, R. G. Oxygen Reduction in Alkaline Solution at Glassy Carbon Surfaces and the Role of Adsorbed Intermediates. J. Electroanal. Chem. 2017, 799, 53-60.

31. Xiong, L.; Aldous, L.; Henstridge, M. C.; Compton, R. G. Investigation of the Optimal Transient Times for Chronoamperometric Analysis of Diffusion Coefficients and Concentrations in Non-aqueous Solvents and Ionic Liquids. Anal. Methods 2012, 4, 371-376.

32. Compton, R. G.; Banks, C. E. Understanding Voltammetry. Imperial College Press: London, UK, 2011.

33. Thapa, S. K.; Adhikari, N. P. A Molecular Dynamics Study of Oxygen Gas in Water at Different Temperatures. Int. J. Mod. Phys. B 2013, 27, 1350023. 